\title{
Desenvolvimentismo e neodesenvolvimentismo: tragédia e farsa
}

\section{Developmentalism and new developmentalism: tragedy and farce}

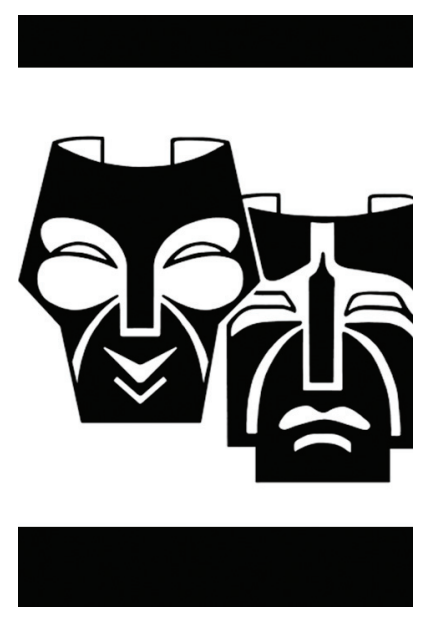

Plínio de Arruda Sampaio Jr. ${ }^{*}$

Resumo: A pretensão do neodesenvolvimentismo de pleitear a continuidade do desenvolvimentismo não encontra nenhum fundamento objetivo. As duas expressões do pensamento econômico correspondem a épocas históricas distintas e representam espectros ideológicos opostos. Ao identificar a realidade da economia brasileira contemporânea com o desenvolvimento capitalista virtuoso, o novo desenvolvimentista revela-se tal qual é - uma apologia do poder. Não passa de um esforço provinciano para dar roupa nova à velha teoria da modernização como solução para os graves problemas das populações que vivem no elo fraco do sistema capitalista mundial.

Palavras-chave: Desenvolvimentismo. Neodesenvolvimentismo. Dependência. Subdesenvolvimento. Revolução burguesa. Crescimento com equidade. Economia brasileira. Reversão neocolonial.

\begin{abstract}
The pretension of the new developmentalism to plead the continuity of the old developmentalism has no objective foundation. The two expressions of economic thought correspond to different historical epochs and represent opposing sides of the ideological spectrum. When the new developmentalism identifies the contemporary reality of the Brazilian economy with virtuous capitalist development, it reveals what it is really: an apologia for power. It is nothing more than a parochial effort to make up the old theory of modernization as a solution to the serious problems of the population living in the weak link of the capitalist world system.
\end{abstract}

Keywords: Developmentalism. New developmentalism. Dependency. Underdevelopment. Bourgeois revolution. Growth with equity. Brazilian economy. Neo-colonial reversion.

* Professor do Instituto de Economia da Universidade Estadual de Campinas — IE/Unicamp/São Paulo, Brasil.E-mail: pasampaiojr@gmail.com. 


\section{Introdução}

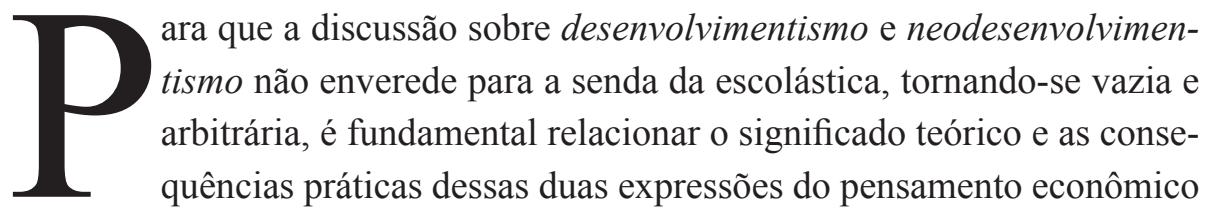

a seus respectivos contextos históricos. Tal contraposição revelará o abismo que existe entre a ideologia burguesa como utopia - expressão trágica de uma vontade política que não tinha condições históricas para se concretizar - e a ideologia burguesa como farsa - expressão falsificada de uma realidade que nega os próprios fundamentos da noção de desenvolvimento.

A argumentação será desdobrada em quatro movimentos. Na seção ii apresentaremos uma síntese das principais teses do desenvolvimentismo, associando-as ao contexto histórico que as engendrou. Na seção iii resumimos os condicionantes históricos que solaparam as bases sociais e políticas do desenvolvimentismo e caracterizamos, em grandes pinceladas, o sentido mais geral do processo de revisão que diluiu suas bases teóricas fundamentais. Na seção iv expomos as linhas mestras do neodesenvolvimentismo, destacando a sua relação com a conjuntura muito particular que o condicionou. Por fim, concluímos, na seção v, com um balanço sobre o significado real dessa nova onda que anima acaloradas tertúlias entre acadêmicos heterodoxos simpáticos ao bloco de poder que governa o Brasil desde 2002.

\section{0 desenvolvimento nacional como utopia burguesa}

O desenvolvimentismo é um termo vago utilizado para designar o pensamento crítico sobre os dilemas e os desafios do desenvolvimento nacional nas economias latino-americanas enredadas no círculo vicioso da dependência e do subdesenvolvimento. O centro dessa reflexão consiste no esforço de equacionar os nós que devem ser desatados para que a expansão das forças produtivas possa ser associada à solução dos problemas fundamentais da população. Nessa perspectiva, acumulação de capital, avanço das forças produtivas e integração 
nacional constituem aspectos indissolúveis de um mesmo problema: criar as bases materiais, sociais e culturais de uma sociedade nacional capaz de controlar o sentido, o ritmo e a intensidade do desenvolvimento capitalista. O desenvolvimentismo foi, portanto, uma arma ideológica das forças econômicas e sociais que, no momento decisivo de cristalização das estruturas da economia e da sociedade burguesa, se batiam pela utopia de um capitalismo domesticado, subordinado aos desígnios da sociedade nacional. ${ }^{1}$

Tendo como eixo articulador a preocupação em integrar industrialização e formação da economia nacional, o desenvolvimentismo relaciona a especificidade do capitalismo na América Latina à perpetuação de uma dupla articulação que compromete a capacidade de a sociedade nacional controlar os fins e os meios de desenvolvimento - a situação de dependência externa e a extrema desigualdade entre as classes sociais. A subordinação da vida econômica nacional à lógica ultraespeculativa do capital internacional e à reprodução de estruturas sociais típicas de regimes de segregação social distorcem irremediavelmente as propriedades construtivas da concorrência econômica e da luta de classes - molas propulsoras do desenvolvimento capitalista autodeterminado. A superexploração do trabalho, a irracionalidade do processo de incorporação de progresso técnico, a instabilidade econômica e financeira, o espectro da estagnação e as crises cíclicas de reversão estrutural tornam-se características inerentes ao capitalismo na periferia latino-americana da economia mundial.

O diagnóstico crítico elaborado pelos desenvolvimentistas implica a necessidade inescapável de "mudanças estruturais" que ataquem as causas do subdesenvolvimento. Por conseguinte, a sua agenda política passa pelo enfrentamento do imperialismo, que submete as economias periféricas aos imperativos do desenvolvimento desigual e combinado, bem como por reformas estruturais que liquidem as bases objetivas e subjetivas do regime de segregação social - o latifúndio e os privilégios aberrantes de burguesias dependentes, cuja força se alimenta na pobreza e na miséria de expressivos contingentes da população. Por diferentes caminhos, as formulações desenvolvimentistas partiam do suposto de que as estruturas que bloqueavam o desenvolvimento ca-

1. Para uma discussão detalhada sobre a problemática do desenvolvimento no capitalismo dependente ver Sampaio Jr., $1999 a$. 
pitalista nacional eram produto de contingências históricas que poderiam ser superadas pela "vontade política" nacional. Não haveria nenhum obstáculo intransponível que impedisse, inescapavelmente, a possibilidade de conciliar capitalismo, democracia e soberania nacional nas economias da periferia do sistema imperialista.

Nessa perspectiva, a superação do capitalismo selvagem não poderia ser concebida como resultado natural e espontâneo do desenvolvimento capitalista. Sem mudanças de grande envergadura, o crescimento e a modernização não resolveriam as mazelas da população. $\mathrm{O}$ desenvolvimento nacional supunha a subordinação da acumulação capitalista a uma "vontade" coletiva que integrasse o conjunto da população nos benefícios do progresso técnico. A importância decisiva da intervenção transformadora do homem como único meio de romper o círculo vicioso do subdesenvolvimento vinculava, assim, o destino do "desenvolvimentismo" à presença de sujeitos sociais dispostos a enfrentar o problema da integração nacional em todas as dimensões - econômica, social, regional, política e cultural. Sem a presença de burguesias nacionais capazes de enfrentar os interesses externos e internos comprometidos com a reprodução da situação de dependência e subdesenvolvimento, a concepção "desenvolvimentista" pereceria, pois não teria como se converter em força real. A sorte do "desenvolvimentismo" confundia-se, assim, com o próprio destino de formação da sociedade nacional. ${ }^{2}$

Na história da América Latina, a gênese e a falência do "desenvolvimentismo" foram condicionadas pelo apogeu e declínio do processo de industrialização por substituição de importações. A reflexão sobre o papel estratégico da industrialização como base de um sistema econômico nacional respondia às necessidades concretas de sociedades nacionais que se encontravam na encruzilhada decisiva de sua formação como sociedade nacional. Logo, a construção da indústria nacional, a organização de centros internos de decisão, a formação da intelligentsia nacional, a consolidação de projetos nacionais que orientassem a ação da política econômica e o desenvolvimentismo como expressão de uma consciência crítica sobre a natureza dos problemas nacionais faziam parte de

2. A problemática da formação como elemento essencial do desenvolvimento nacional é examinada em Ianni, 1992. 
um mesmo processo, cujo sentido histórico estava indissoluvelmente relacionado com o desfecho da revolução burguesa no continente nas décadas de 1950 e 1960. A expressão máxima dessa corrente de pensamento, que representava no plano das ideias os sonhos românticos das facções burguesas progressistas, está associada aos trabalhos de Raúl Prebisch, que estabeleceram as bases da economia política da Cepal. ${ }^{3}$ No Brasil, a crítica ao subdesenvolvimento alcançou sua forma mais elaborada nos trabalhos teóricos e nas análises históricas de Celso Furtado. ${ }^{4}$

\section{A fantasia desfeita e a negação do "desenvolvimentismo"}

Iniciado no Brasil em 1964 e encerrado no Chile em 1973, o ciclo latino-americano de golpes militares que instauram ditaduras do grande capital determina o desfecho do processo de revolução burguesa no continente como uma contrarrevolução permanente. O regime do capital consolida-se na América Latina como um capitalismo dependente. Apoiadas pelo império norte-americano, os setores pragmáticos interromperam violentamente o processo de reformas estruturais, cristalizando definitivamente a dupla articulação — dependência externa e segregação social — como alicerce fundamental da acumulação de capital na região. A contrarrevolução jogou por terra os sonhos desenvolvimentistas. ${ }^{5} \mathrm{O}$ regime burguês sedimentou-se como uma sociedade mercantil particularmente antissocial, antinacional e antidemocrática. A superexploração do trabalho tornou-se parâmetro estratégico do padrão de acumulação. A intolerância em relação à utilização do conflito como meio legítimo de conquistas coletivas converteu-se na quintessência do padrão de dominação. Pobreza e miséria se transformaram definitivamente na galinha de ovos de ouro da burguesia latino-americana. Acabava a ilusão de um capi-

\footnotetext{
3. A economia política latino-americana encontra-se sistematizada no trabalho de Rodriguez, 1981.

4. Para uma análise detalhada da evolução do pensamento de Furtado, ver Mallorquin, 2005. O limite da crítica de Furtado é examinado em Sampaio Jr., $2009 a$.

5. Furtado faz um detalhado balanço do impacto do ciclo das ditaduras militares sobre sua visão de mundo em Furtado, 1989.
} 
talismo civilizado. O brutal desequilíbrio na correlação de forças entre capital e trabalho tornou-se premissa fundamental do capitalismo no continente. ${ }^{6}$

O novo contexto histórico determinou uma revisão radical das bases teóricas do estruturalismo desenvolvimentista, cuja essência consiste na dissolução absoluta da dupla articulação como o problema fundamental da sociedade latino-americana. Primeiro, diluiu-se a contradição entre imperialismo e desenvolvimento. O capital internacional deixou de ser visto como empecilho ao desenvolvimento para se converter em condição sine qua non do próprio desenvolvimento. O trabalho de Fernando Henrique Cardoso e Enzo Faletto, Dependência e desenvolvimento (2004), foi pioneiro no movimento teórico de harmonização das contradições provocadas pela situação de dependência. Logo em seguida foi diluída a contradição entre pobreza e desenvolvimento capitalista autodeterminado. A integração social deixou de ser vista como obstáculo à incorporação de progresso técnico - pré-requisito do próprio desenvolvimento - para se converter em resíduo colonial sem maiores consequências para o dinamismo capitalista. Além da Estagnação, de Maria da Conceição Tavares e José Serra (1972), é a referência básica dessa nova concepção que oculta o nexo entre modernização dos padrões de consumo, tendência estrutural à concentração de renda e subdesenvolvimento. Ao reduzir desenvolvimento ao simples processo de industrialização e modernização, deixando de lado a questão da autonomia nacional e o problema da integração social, lançavam-se as bases para uma profunda ressignificação do próprio conceito de desenvolvimento.?

Reduzida à relação entre acumulação de capital e modernização dos padrões de consumo, a problemática do desenvolvimento transforma-se em problemática do desenvolvimento capitalista. Antes de superar as insuficiências do desenvolvimentismo, o movimento revisionista negava a própria realidade do subdesenvolvimento. A relação necessária de condicionamento mútuo entre

6. Sobre os condicionantes e o significado da revolução burguesa no Brasil ver, Fernandes, 1976, e Ianni, 1981.

7. O contexto histórico que condicionou o processo de revisão é sistematizado em Faletto, 1998, p. 109-117. O movimento de revisão crítica que resulta na negação da problemática desenvolvimentista é analisado com mais detalhe em Sampaio Jr., $1999 b$. 
industrialização e formação da economia nacional estava definitivamente rompida. Enfim, impugnava-se a própria noção de subdesenvolvimento como uma realidade composta pela totalidade de nexos orgânicos entre: controle da economia pelo capital internacional, latifúndio, desemprego estrutural, marginalidade social, inadequação tecnológica, heterogeneidade estrutural, estreiteza e precariedade do mercado interno, controle do Estado por burguesias aculturadas, modernização dos padrões de consumo, posição subalterna na divisão internacional do trabalho, transferência de recursos ao exterior, tendência estrutural a concentração do progresso técnico, colonialismo interno, instabilidade monetária, tendência estrutural à estagnação, fragilidade fiscal, deterioração dos termos de troca, tendência estrutural a desequilíbrios externos, irracionalidade econômica, dependência tecnológica, financeira e cultural, precariedade dos centros internos de decisão, ameaça permanente de crises de reversão estrutural.

\section{0 neodesenvolvimentismo como simulacro do desenvolvimento}

O chamado neodesenvolvimentismo é um fenômeno recente e localizado, indissociável das particularidades da economia e da política brasileiras na segunda metade dos anos 2000. Sua repercussão não ultrapassa as fronteiras da "província" e, mesmo no seu interior, circunscreve-se a pequenos círculos acadêmicos. Mais do que uma nova tendência do pensamento econômico com fôlego para se expandir a outras praças e resistir à prova do tempo, a onda neodesenvolvimentista está diretamente relacionada às intrigas e conspirações palacianas entre as duas facções que disputam o controle da política econômica brasileira: a monetarista - braço direito do neoliberalismo - e a autoproclamada "desenvolvimentista" - braço esquerdo da ordem. Fenômeno análogo já tinha se esboçado no primeiro governo de Fernando Henrique Cardoso, contrapondo as diretrizes do Banco Central, liderado por Gustavo Franco, às políticas do BNDES, então sob a influência dos irmãos Mendonça de Barros. $\mathrm{Na}$ época, a escaramuça já surgiu natimorta porque o choque entre teoria e prática era gritante. A crise de estrangulamento cambial e a subsequente tutela da política econômica pelo FMI jogavam por terra qualquer possibilidade de 
camuflar a absoluta impotência do Estado brasileiro diante dos ditames do capital financeiro.

A situação que se cristaliza a partir do segundo governo Lula é diferente. A modesta retomada do crescimento econômico, após quase três décadas de estagnação, a lenta recuperação do poder aquisitivo do salário após décadas de arrocho, a ligeira melhoria na distribuição pessoal da renda, o boom de consumo financiado pelo endividamento das famílias e a aparente resiliência do Brasil perante a crise econômica mundial dão um lastro mínimo de realidade à fantasiosa falácia de que, finalmente, o Brasil estaria vivendo um ciclo de desenvolvimento. O chamado neodesenvolvimentismo seria, assim, uma expressão teórica desse novo tempo. Para alguns de seus adeptos mais ingênuos que acreditam fervorosamente no poder criador das fórmulas abstratas, as novas ideias seriam, na verdade, a própria causa determinante da guinada qualitativa na trajetória da economia brasileira.

Acima de suas diferenças e idiossincrasias de ordem teórica e prática, os economistas que reivindicam o novo desenvolvimentismo compartilham um denominador comum: procuram uma terceira via que evite o que consideram o grave problema do neoliberalismo - a cumplicidade com o rentismo - e o que atribuem como as inaceitáveis perversidades do velho desenvolvimentismo - o nacionalismo anacrônico, a complacência com a inflação e o populismo fiscal. O desafio do neodesenvolvimentismo consiste, portanto, em conciliar os aspectos "positivos" do neoliberalismo - compromisso incondicional com a estabilidade da moeda, austeridade fiscal, busca de competitividade internacional, ausência de qualquer tipo de discriminação contra o capital internacional - com os aspectos "positivos" do velho desenvolvimentismo - comprometimento com o crescimento econômico, industrialização, papel regulador do Estado, sensibilidade social. ${ }^{8}$

As vagas formulações dos economistas que disputam a hegemonia do novo desenvolvimentismo partem do suposto de que o crescimento constitui a chave para o enfrentamento das desigualdades sociais. Nessa perspectiva, desenvolvimento e crescimento confundem-se como fenômenos indiferenciados. As

8. Sobre as formulações que compõem o neodesenvolvimentismo ver: Branco, 2009. (Bresser-Pereira, Fonseca, Cunha, Bichara, maio 2012, Mattei, ago. 2011, Sicsú, Paula, Michel, 2005). 
controvérsias dizem respeito às formas de superar os aspectos "negativos" e ao modo de combinar os aspectos "positivos". O debate gira em torno dos instrumentos que devem ser mobilizados pela política econômica para superar os entraves ao crescimento e conciliar as exigências do equilíbrio macroeconômico com os objetivos da política industrial e as necessidades orçamentárias da política social. Não se coloca em questão a dupla articulação — dependência externa e segregação social - responsável pela continuidade do capitalismo selvagem. O impacto devastador da ordem global sobre o processo de formação da economia brasileira não é considerado. Tampouco são examinados a fundo os efeitos de longo prazo da crise econômica mundial sobre a posição do Brasil na divisão internacional do trabalho. A discussão não ultrapassa o horizonte da conjuntura imediata.

A obsessão em depurar o lado "negativo" e condensar os aspectos "positivos" dos dois polos que condicionam o novo desenvolvimentismo assume a forma de um hibridismo acrítico que se afirma menos pela originalidade de sua interpretação e mais pela contraposição de suas proposições alternativas aos dogmas da ortodoxia. Assim, toda a reflexão neodesenvolvimentista enquadra-se perfeitamente na pauta neoliberal. Na prática, a terceira via torna-se uma espécie de versão ultra light da estratégia de ajuste da economia brasileira aos imperativos do capital financeiro. O diferencial do neodesenvolvimentismo se resume ao esforço de atenuar os efeitos mais deletérios da ordem global sobre o crescimento, o parque industrial nacional e a desigualdade social. Não se questiona a possibilidade de a igualdade social e a soberania nacional serem simplesmente antagônicas com a estabilidade da moeda, a austeridade fiscal, a disciplina monetária, a busca incessante da competitividade internacional, a liberalização da economia. Procura-se o segredo da quadratura do círculo que permita conciliar crescimento e equidade.

Ao identificar as suas utopias com a realidade concreta da economia brasileira, o neodesenvolvimentismo revela o seu lado simplório e provinciano, apresentando-se como é: uma grosseira apologia da ordem. O método de ocultação sistemática do negativo e de exaltação acrítica do crescimento e da modernização dos padrões de consumo como fins em si transforma o vício em virtude. A relação indissolúvel entre desenvolvimento e barbárie característica de 
nosso tempo, que se manifesta com virulência redobrada nas economias periféricas, converte-se, assim, por um passe de mágica no seu contrário: o desenvolvimento capitalista virtuoso capaz de conciliar crescimento com equidade. A supervalorização dos fatos considerados positivos e a pura e simples desconsideração dos aspectos negativos da realidade alimentam a mitologia de que a economia brasileira estaria passando por um ciclo endógeno de crescimento com distribuição de renda e aumento da soberania nacional. ${ }^{9}$

Atendo-se aos horizontes restritos da macroeconomia, cujos parâmetros baseiam-se na suposição de que os fundamentos da realidade não sofrem alterações qualitativas, a perspectiva neodesenvolvimentistas fica impedida, como consequência de suas próprias escolhas epistemológicas, de examinar os fenômenos do desenvolvimento, cuja essência consiste em compreender a capacidade de a sociedade nacional controlar o processo de mudança social impulsionado pela acumulação de capital. Ao ignorar as contradições estruturais que regem o movimento da economia brasileira, o neodesenvolvimentismo incorre num vulgar reducionismo economicista e simplesmente renuncia à problemática do desenvolvimento. Seus modelos explicativos partem de parâmetros dados, sem questionar os efeitos determinantes desses parâmetros sobre o desempenho econômico, quando, a rigor, para ser fiel à tradição crítica, o correto seria fazer o caminho inverso: mostrar a relação entre os parâmetros que determinam o funcionamento da economia brasileira - a dupla articulação - e a incapacidade de a sociedade brasileira controlar o desenvolvimento capitalista que determina a sua submissão ao círculo de ferro da dependência e subdesenvolvimento. Na nova perspectiva, portanto, o desenvolvimento é apenas um simulacro - crescimento e modernização são alçados à condição de desenvolvimento. ${ }^{10} \mathrm{~A}$ aparência crítica é apenas um disfarce para a apologia do status quo.

9. A apologia neodesenvolvimentista beira as raias da pura e simples propaganda na tese de doutorado de Mercadante, 2010. Para uma análise crítica dos mitos do governo Lula, baseada em dados empíricos, ver excelente síntese de Gonçalves, 2002, p. 5-30.

10. Ainda que muitos autores neodesenvolvimentistas reivindiquem explicitamente o legado de Celso Furtado, curiosamente, nenhum deles sequer menciona sua implacável crítica à perspectiva economicista para o entendimento dos problemas do desenvolvimento. As razões de Furtado encontram-se sistematizada em Furtado, 1976. 


\section{Ordem global, reversão neocolonial e neodesenvolvimentismo}

A abstração dos condicionantes estruturais que determinam a forma específica de funcionamento da economia brasileira impede a percepção dos interesses estratégicos, internos e externos, responsáveis pela continuidade da dupla articulação e seus efeitos perversos sobre a capacidade de a sociedade nacional controlar os fins e os meios do processo de incorporação de progresso técnico. Perdem-se os elos inextrincáveis entre presença dominante do capital internacional, vulnerabilidade externa estrutural, desindustrialização e especialização regressiva das forças produtivas. Desaparecem os nexos entre burguesia dos negócios, especulação mercantil e financeira como base da acumulação capitalista, dependência estrutural da exportação de commodities e revitalização do latifúndio e do extrativismo - estruturas típicas da economia colonial. Por fim, a opção por ficar na superfície dos fenômenos impede que se vejam os vínculos indissolúveis entre burguesias rentistas, discriminação contra o investimento produtivo, ajuste fiscal permanente, limites estruturais à expansão do mercado interno e precariedade das políticas públicas. Sem colocar em evidência os poderosos interesses burgueses externos e internos que devem ser enfrentados para que se possam abrir novos horizontes para o desenvolvimento, os neodesenvolvimentistas ficam presos ao fim da história.

A ausência de uma perspectiva totalizante da política econômica não permite que os defensores do novo desenvolvimentismo percebam a complexidade da teia institucional que ata de maneira inescapável o Estado brasileiro aos interesses do grande capital internacional e nacional e estes à perpetuação da dupla articulação — dependência externa e segregação social. A perda da perspectiva do todo faz desaparecer não apenas os vínculos orgânicos entre os diversos componentes do ajuste liberal (processo de liberalização, desregulamentação e privatização, estabilidade da moeda, Lei de Responsabilidade Fiscal, superávits primários, limite ao endividamento do setor público, ataque aos direitos trabalhistas), como também os efeitos da ordem global sobre as condições de funcionamento da economia brasileira (livre mobilidade dos capitais, perda de soberania monetária, impotência dos centros internos de decisão diante dos movimentos especulativos do capital internacional, restrição à expansão do 
mercado interno, bloqueios à política industrial, antagonismo entre políticas macroeconômicas e gasto público, concorrência entre políticas sociais universalistas e políticas sociais assistencialistas). É impossível imaginar brechas para mudanças parciais que possam provocar transformações substanciais no padrão de desenvolvimento da economia brasileira sem uma profunda e radical ruptura com a institucionalidade vigente. É uma ingenuidade imaginar que a ordem global possa ser rompida pelas "beiradas", pois a institucionalidade liberal funciona como uma amarra muito bem urdida, que prende o país cada vez mais nas garras do capital financeiro.

A inconsciência em relação à adversidade do contexto histórico leva o neodesenvolvimentismo a inverter o significado do processo histórico em curso que determina uma relação inescapável entre desenvolvimento capitalista e barbárie. ${ }^{11}$ No que diz respeito aos condicionantes mais gerais do desenvolvimento, a inversão implica a abstração das características do capitalismo contemporâneo que comprometem a capacidade de as sociedades nacionais, mesmo as mais desenvolvidas, controlarem o seu destino. O neodesenvolvimentismo só pode fantasiar sobre a possibilidade de um desenvolvimento capitalista nacional porque ignora os encadeamentos necessários entre concentração e centralização dos capitais, dominância absoluta do capital financeiro sobre o processo de acumulação, lógica de império que preside a ação das potências imperialistas (Estados Unidos à frente), total subordinação da ordem econômica mundial aos imperativos do capital financeiro, incontrolabilidade do capital, crise terminal do keynesianismo e tendência à reversão neocolonial nos países que fazem parte da periferia da economia mundial. No que se refere à peculiaridade da situação do Brasil no contexto mundial, a inversão da realidade assume a forma de uma desconsideração do impacto particularmente devastador da etapa superior do imperialismo sobre todas as dimensões da vida nacional. ${ }^{12} \mathrm{~A}$ perspectiva economicista não permite enxergar os processos que impulsionam o movimento de reversão neocolonial, pois oculta a relação entre o ajuste às

11. O contexto histórico gerado pela crise estrutural do capital é objeto do estudo de Mészáros, 2002. Para uma visão sintética da relação entre capitalismo e barbárie, ver Sweezy, 1994; e Mészáros, 2003. A relação entre a crise estrutural do capital e o processo de reversão neocolonial é examinada em Sampaio Jr., 2011a.

12. Sobre a posição particularmente vulnerável do Brasil na ordem global ver Furtado, 1992. 
exigências da ordem global, a regressão das forças produtivas, a desnacionalização da economia, a naturalização da desigualdade social, a crise federativa, a desarticulação dos centros internos de decisão e a crise da identidade nacional.

Por fim, a expectativa delirante de que o Brasil venha a patrocinar o milagre do desenvolvimento capitalista em um só país, em meio à mais grave crise econômica da história do capitalismo monopolista, é possível apenas porque o neodesenvolvimentismo desconsidera completamente os efeitos perversos de uma conjuntura econômica marcada pela necessidade de digerir um monumental excedente absoluto de capital, pelo caráter ultrarregressivo da solução americana para a crise (que implica uma aposta dobrada no liberalismo), pelo impacto devastador do movimento de desdobramento da crise pelo mundo (que combina especulação e ajuste estrutural como formas perversas de transferência do ônus da crise para o elo fraco do sistema capitalista mundial). ${ }^{13}$

A ausência de uma avaliação consubstanciada dos efeitos da crise econômica mundial sobre a economia brasileira não permite que se perceba que, por trás da aparente resiliência do Brasil aos efeitos da crise, existem transformações estruturais de grande envergadura que aprofundam e aceleram o processo de reversão neocolonial. Ao omitir as terríveis contradições geradas pela crise econômica mundial, o neodesenvolvimentismo não precisa explicar os nexos inexoráveis entre o crescimento econômico impulsionado pela bolha especulativa global, a revitalização da economia exportadora baseada no latifúndio e no extrativismo, o avanço irreversível da desindustrialização e o espectro de uma crise cambial e financeira de dimensão cataclísmica como desfecho inexorável da farra especulativa financiada pela entrada indiscriminada de capital internacional. Por mais que os trompetes toquem, a apologia da ordem não é capaz, porém, de mudar a dura realidade dos fatos. Sem competitividade dinâmica para enfrentar a concorrência dos países desenvolvidos e sem competitividade espúria para disputar mercados com os países da periferia industrializada que recorrem a relações de exploração ainda mais primitivas (China, por exemplo), só resta à burguesia brasileira uma posição ainda mais subalterna na divisão internacional do trabalho. Nesse contexto, antes de um processo sustentável de de-

13. A interpretação da crise que fundamenta a análise subsequente encontra-se em: Sampaio Jr., 2009; Sampaio Jr., 2010 e 2011b. 
senvolvimento, a sociedade brasileira deve esperar novos ataques aos direitos dos trabalhadores e às políticas públicas — única variável de ajuste que resta às burguesias locais para fazer face ao acirramento da concorrência internacional.

A distância entre desenvolvimentismo e neodesenvolvimentismo é proporcional ao fosso que separa duas épocas históricas radicalmente distintas. A economia política da Cepal representava a crítica da ordem e a aposta na possibilidade de mudanças estruturais que criassem as condições objetivas e subjetivas para que se pudesse conciliar capitalismo, democracia e soberania nacional. Ao transformar o Brasil em modelo, o neodesenvolvimentismo não passa de uma tosca apologia da ordem. A perspectiva do velho desenvolvimentismo é um esforço de mostrar a necessidade inescapável de "reformas estruturais" que desatem a dupla articulação responsável pelo caráter particularmente selvagem do capitalismo na periferia do sistema capitalista mundial. O neodesenvolvimentismo naturaliza a dupla articulação responsável pelo capitalismo dependente. Suas formulações ficam limitadas a elucubrações sobre a possibilidade de arquiteturas alternativas de política econômica para administrar as estruturas. A perspectiva desenvolvimentista supõe a presença de sujeitos políticos dispostos a enfrentar o imperialismo e o latifúndio. Os novos desenvolvimentistas são entusiastas do capital internacional, do agronegócio e dos negócios extrativistas. Defendem a estabilidade da ordem. Não alimentam nenhuma pretensão de que seja possível e mesmo desejável mudanças qualitativas no curso da história. São entusiastas do status quo. Na sua visão de mundo, desenvolvimento e fim da história caminham de mãos dadas.

Existe, portanto, uma incongruência absoluta entre o que o neodesenvolvimentismo pensa ser - uma alternativa qualitativa de desenvolvimento capaz de resolver os problemas renitentes da pobreza e da dependência externa - e o que é de fato: apenas uma nova versão da surrada teoria do crescimento e da modernização acelerada como solução para os problemas do Brasil. Nada mais do que isso. Além de seu papel nas lutas intestinas da burocracia que comanda a política econômica, o "neodesenvolvimentismo" cumpre uma dupla função como arma ideológica dos grupos políticos entrincheirados nas estruturas do 
Estado: diferencia o governo Lula do governo FHC, lançando sobre este último a pecha de "neoliberal" e reforça o mito do crescimento como solução para os problemas do país, iludindo as massas.

As promessas vazias de um desenvolvimento capitalista virtuoso que nunca se realiza não deixam margem a dúvidas. $\mathrm{O}$ verdadeiro resgate da tradição crítica do pensamento latino-americano passa pela superação de toda ilusão em relação à existência de uma solução burguesa para a tragédia do subdesenvolvimento e da dependência. $\mathrm{O}$ caminho da crítica encontra-se no polo oposto da perspectiva provinciana, das opções de classe e das escolhas teóricas dos neodesenvolvimentistas.

Recebido em 6/8/2012 - Aprovado em 15/8/2012

\section{Referências bibliográficas}

BRANCO, R. C. O novo-desenvolvimentismo e a decadência ideológica do estruturalismo latino-americano. Oikos, Rio de Janeiro, v. 8, n. 1, 2009. Disponível em: <http:// www.revistaoikos.otg/seer/index.php/oikos/article/view/132/111>. Acesso em: 30 jul. 2012.

BRESSER-PEREIRA, L. C. Do antigo ao novo desenvolvimentismo na América Latina. Texto para Discussão, São Paulo, n. 275, nov. 2010. Disponível em: $<$ http://bibliotecadigital.fgv.br/dspace/bitstream/handle/10438/7726/TD\%20274\%20-\%20 Luiz\%20Carlos\%20Bresser\%20Pereira.pdf?sequence=1>. Acesso em: 30 jul. 2012.

CARDOSO, Fernando. H.; FALETTO, Enzo. Dependência e desenvolvimento na América Latina. Rio de Janeiro: Civilização Brasileira, 2004.

FALETTO, E. Los años 60 y el tema de la dependencia. Estudos Avançados da USP, São Paulo, v. 12, n. 33, p. 109-117, ago. 1998.

FERNANDES, F. A revolução burguesa no Brasil: ensaio de interpretação sociológica. Rio de Janeiro: Zahar, 1976.

FONSECA, P. C. D.; CUNHA, A. M.; BICHARA, J. S. O Brasil na era Lula: retorno ao desenvolvimentismo? Texto para Discussão, São Paulo, n. 4 (Rede Desenvolvimentista), maio 2012. Disponível em: $<$ http://www.reded.net.br/index.php?option= 
com_jdownloads \&Itemid=183\&view=viewdownload\&catid=14\&cid=179\& lang=pt\#.T-f2rLW0z_M>. Acesso em: 30 jul. 2012.

FURTADO, C. A fantasia desfeita. Rio de Janeiro: Paz e Terra, 1989.

. Brasil: a construção interrompida. Rio de Janeiro: Paz e Terra, 1992.

. Prefácio à nova economia política. Rio de Janeiro: Paz e Terra, 1976.

GONÇALVES, Reinaldo. Governo Lula e o nacional-desenvolvimentismo às avessas. Revista da Sociedade Brasileira e Economia Política, São Paulo, n. 31, fev. 2002.

IANNI, O. O ciclo da revolução burguesa no Brasil. Temas de Ciências Humanas, São Paulo, n. 10, 1981. . A ideia de Brasil moderno. São Paulo: Brasiliense, 1992.

MALLORQUIN, C. Celso Furtado: um retrato intelectual. Rio de Janeiro: Contraponto, 2005.

MATTEI, L. Gênese e agenda do novo desenvolvimentismo brasileiro. IV Encontro Internacional da Associação Keynesiana Brasileira (AKB), Rio de Janeiro, ago. 2011. Disponível em: $<$ http://www.ppge.ufrgs.br/akb/encontros/2011/10.pdf > . Acesso em: 30 jul. 2012.

MERCADANTE, Aloísio. As bases do novo desenvolvimentismo: análise do governo Lula. Tese (Doutorado) - Instituto de Economia da Universidade Estadual de Campinas - IE Unicamp, Campinas, 2010.

MÉSZÁROS, I. Para além do capital. São Paulo: Boitempo, 2002.

. Século XXI: capitalismo ou barbárie. São Paulo: Boitempo, 2003.

RODRIGUEZ, O. Teoria do subdesenvolvimento da Cepal. Rio de Janeiro: Forense Universitária, 1981.

SAMPAIO JR., P. S. A. Entre a nação e a barbárie: os dilemas do capitalismo dependente. Petrópols: Vozes, 1999a.

. Origem e desdobramento da crise da teoria do desenvolvimento na América

Latina. São Paulo em Perspectiva, São Paulo, v. 13, n.1-2, jan./jun. 1999 b.

. Furtado e os limites da razão burguesa na periferia do capitalismo. Economia —Ensaios, Uberlândia, v. 22, n. 2, $2009 a$.

(Org.). Capitalismo em crise: a natureza e dinâ,ica da crise econômica mundial. São Paulo: Sunderman, $2009 b$. 
SAMPAIO JR., P. S. A. O Brasil não é maior do que a crise. Jornal dos Economistas, Rio de Janeiro, n. 255. out. 2010.

. A crise estrutural do capital e os desafios da revolução. In: JINKINGS, Ivana; NOBILE, Rodrigo (Orgs.). István Mészáros e os desafios do tempo histórico. São Paulo: Boitempo, 2011a.

. Metástase da crise e aprofundamento da reversão neocolonial. Crítica e Sociedade. Uberlândia, v. 1, n. 3, $2011 b$.

SICSÚ, J.; PAULA, L. F.; MICHEL, R. Novo-desenvolvimentismo: um projeto nacional de crescimento com equidade social. São Paulo: Manole, 2005.

SWEEZY, P. The triumph of financial capital. Monthly Review, Nova York, v. 46, n. 2, jun. 1994.

TAVARES, M. C.; Serra, J. Além da estagnação. In: TAVARES, M. C. Da substituição de importações ao capitalismo financeiro. Rio de Janeiro: Zahar, 1972. 